\title{
ROTAS DA COVID-19 NO ESTADO DO MARANHÃO, BR
}

\section{COVID-19 ROUTES IN THE STATE OF MARANHÃO, BR}

\author{
Richard Oliveira Jardim \\ Mestrando em Geografia - Universidade Federal do Maranhão e Bolsista FAPEMA \\ jardim.richard@discente.ufma.br \\ Claudia Rakel Pena Pereira \\ Doutoranda em Geografia - Universidade Federal Fluminense - UFF \\ claudiarakel@id.uff.br
}

Zulimar Márita Ribeiro Rodrigues Programa de Pós-Graduação em Geografia da Universidade Federal do Maranhão zulimar.marita@ufma.br

\begin{abstract}
RESUMO
O processo de transmissão da pandemia da COVID-19 foi favorecido pela rede de hierarquias urbanas. Portanto, a interiorização e aceleração da transmissão ocorreram através das conexões e fluxos de pessoas e mercadorias. Dessa forma, buscou-se discutir como o vírus entrou no território maranhense e compreender o processo de expansão da infecção por COVID-19 pelo estado, a partir da análise espacial. Foram utilizados dados secundários, dos casos confirmados, disponibilizados pela Secretaria de Estado da Saúde do Maranhão. Para a confecção dos mapas coropléticos foram utilizadas as bases cartográficas obtidas no Instituto Maranhense de Estudos Socioeconômicos e Cartográficos do Maranhão e Instituto Brasileiro de Geografia e Estatística. Os dados foram trabalhados utilizando o software QGIS 3.18.2. Inicialmente foram identificadas três cidades de entrada dos casos confirmados no estado, São Luís, Imperatriz e Timon; posteriormente, houve a interiorização em praticamente todo o estado através do fluxo de pessoas e mercadorias, devido ao grau de influência ou subordinação dos centros urbanos.
\end{abstract}

Palavras-chave: Pandemia. Rede Urbana. Análise Espacial.

\section{ABSTRACT}

The COVID-19 pandemic transmission process was favored by the network of urban hierarchies. Therefore, the internalization and acceleration of transmission occurred through the connections and flows of people and goods. Thus, we sought to discuss how the virus entered the territory of Maranhão and understand the process of expansion of infection by COVID-19 by the state, based on spatial analysis. Secondary data, from confirmed cases, made available by the State Secretariat of Health of Maranhão, were used. The cartographic bases obtained from the Maranhense Institute of Socioeconomic and Cartographic Studies of Maranhão, and the Brazilian Institute of Geography and Statistics were used to make the choropleth maps. The data were processed using the QGIS 3.18.2 software. Initially, three cities of entry for confirmed cases in the state were identified, São Luís, Imperatriz and Timon; subsequently, there was an internalization in practically the entire state, through the flow of people and merchandise, due to the degree of influence or subordination of urban centers.

Keywords: Pandemic. Urban Network. Spatial Analysis.

\section{INTRODUÇÃO}

A Organização Mundial da Saúde (OMS) anunciou em 11 de fevereiro de 2020, o nome de uma nova doença, a COVID-19, causada pelo novo coronavírus (SARS-CoV-2), no sentido literal "Corona Virus Disease (Doença do Coronavírus)"; e "19", em alusão ao ano 2019. O ato de nomear a doença foi

Recebido em: 17/02/2021

Aceito para publicação em: 21/05/2021.

$\begin{array}{lllllll}\text { Hygeia } & \text { Uberlândia - MG } & \text { v. 18 } & 2022 & \text { p. 14-28 } & \text { Página } & 14\end{array}$


necessário para evitar imprecisões de diagnósticos, preconceitos xenofóbicos, grupos de pessoas ou animais (BRASIL, 2020).

O coronavírus faz parte de uma família de vírus conhecida há bastante tempo. Ressalta-se que os primeiros casos de coronavírus em seres humanos foram registrados em 1937, que logo foi isolado. No entanto, foi em 1965 que o vírus foi descrito como coronavírus, em decorrência da sua forma, observada somente por microscópio, que parece uma coroa (BRASIL, 2020). Segundo o Ministério da Saúde do Brasil, a maioria das pessoas se infecta com os coronavírus "comuns" 229E e NL63 e beta coronavírus OC43, HKU1 ao longo da vida, sendo as crianças pequenas as mais propensas a se infectarem.

A infecção por COVID-19 está associada a um evento de grande magnitude, considerada pela OMS como pandemia em 11 de março de 2020. Desde então, tem ocasionado impactos sociais e econômicos negativos aos países onde foram registrados casos dessa nova doença. Destarte, a pandemia passou a representar um grande problema à saúde pública global, dado seu potencial de dispersão, pelo número de casos graves e de óbitos.

Ainda segundo a OMS, o quadro clínico da Covid-19 nos seres humanos pode variar de infecções assintomáticas aos quadros respiratórios graves. Desta maneira, cerca de $80 \%$ podem ser assintomáticos, $20 \%$ dos casos podem requerer atendimento hospitalar por apresentarem dificuldade respiratória e desses casos aproximadamente $5 \%$ podem necessitar de suporte para o tratamento de insuficiência respiratória (suporte ventilatório).

No mundo, a disseminação da Covid-19 se deu de forma rápida, desde o primeiro caso ocorrido na China, em 31 de dezembro de 2019. No Brasil, o primeiro caso confirmado pelo Ministério da Saúde foi 26 de fevereiro de 2020; no estado do Maranhão, em 20 de março, conforme declarou a Secretária de Saúde do Estado.

A rápida disseminação da doença, por vários países, teve como principal indutor a circulação de pessoas e mercadorias, diante do cenário de uma economia globalizada. Portanto, partimos do pressuposto que o vírus "viajou" através da rapidez dos atuais sistemas de transportes aéreos, terrestres e marítimos. E sua dispersão foi ainda favorecida pela rede de hierarquias urbanas, chegou primeiro nas maiores cidades (que exercessem influência) e, posteriormente, nas menores (que são subordinadas).

A rede urbana de um país reflete em grande medida o nível de integração dos sistemas produtivo, financeiro e sociocultural em seu território. Esta rede, por sua vez, também influência a forma como aqueles sistemas se organizam territorialmente por processos econômicos e sociais, lócus de tomada de decisão (CORRÊA, 1995; OLIVEIRA, 2005 e 2007). De acordo com Pereira e Furtado (2011), a noção de rede urbana manifesta características históricas e geográficas de um determinado território, assim como as conexões das redes técnicas de transportes e telecomunicações manifestam decisões de investimento de médio e longo prazo.

A rede urbana brasileira é constituída por centros que polarizam a economia, o fluxo de pessoas e a oferta de bens e serviços. De acordo com o Instituto Brasileiro de Geografia e Estatística (IBGE), o Brasil tem 5.570 municípios, mas a rede urbana é comandada por 11 centros. Desses, 49 são aglomerações urbanas, 440 cidades são consideradas centros urbanos, além do Distrito Federal. Esses centros urbanos reúnem $60 \%$ da população do país. Rio de Janeiro e São Paulo concentram $18 \%$ da população brasileira e são consideradas metrópoles globais (IBGE, 2010).

As aglomerações urbanas podem ou não ser metropolitanas, concentram quase $50 \%$ da população e estão distribuídas em 379 cidades. São consideradas metrópoles nacionais: Salvador-BA, Belo Horizonte-MG, Fortaleza-CE, Brasília-DF, Curitiba-PR, Recife-PE e Porto Alegre-RS. As cidades de Belém-PA, Goiânia-GO e Campinas-SP são denominadas metrópoles regionais. Já São Luís-MA, Maceió-AL, Natal-RN, Teresina-PI, João Pessoa-PB, São José dos Campos-SP, Ribeirão Preto-SP, Cuiabá-MT, Aracaju-SE, Londrina-PR, Santos-SP, Florianópolis-SC e Vitória-ES são consideradas Capitais Regionais de categoria A (IBGE, 2020).

As cidades, como espaços de concentração tanto de empresas como de pessoas, são por excelência, ambientes favoráveis para a geração de externalidades positivas advindas dessas aglomerações. $\mathrm{Na}$

\begin{tabular}{lllllll}
\hline Hygeia & Uberlândia - MG & v. 18 & 2022 & p. 14-28 & Página & 15
\end{tabular}


escala regional, as cidades constituem-se como elementos-chaves no processo de articulação e comando do espaço, podem ser consideradas a base e o elemento decisivo para o desenvolvimento regional e o ordenamento do território (BRASIL, 2008). Sua capacidade de articulação depende, sobretudo, da sua escala, da natureza da sua base produtiva, de sua localização, da infraestrutura de serviços e equipamentos urbanos, e de transporte que ela oferta.

Dessa forma, a compreensão da dinâmica da rede urbana de um país ou estado, ou dos centros de gestão e as relações entre o território e sua atividade econômica nacional e supranacional ganham importância para além de um amplo diagnóstico de sua economia, são importantes instrumentos de análise para a difusão de problemas de saúde.

O objetivo do trabalho foi discutir como o vírus adentrou no território maranhense e compreender o processo de expansão da infecção por COVID-19 pelo estado, a partir da análise espacial, levando em consideração a rede de conectividade entre as cidades por malhas viárias, bem como a hierarquia da rede urbana.

\section{REDE URBANA MARANHENSE}

O Maranhão é o estado com o menor percentual populacional vivendo em cidades, mas, ainda assim, superou o país no processo de urbanização acelerada dos últimos 50 anos. De uma população calculada em 448.509 habitantes em 1960, o Estado saltou para 4.143.728 em 2010, um crescimento percentual de quase o dobro da Região Nordeste, que no mesmo período cresceu de 7.680.681 para 38.821.246 moradores urbanos. O Estado passou de 91 municípios, em 1960, para 217 em 2000. 136 municípios $(62,6 \%)$ possuem 20 mil habitantes, concentrando $25,85 \%$ do total da população (BURNETT et al., 2016).

De acordo com o último Censo Demográfico de 2010, a distribuição dos habitantes entre as 217 cidades é bastante variada, como mostra o (Quadro 1). 7 cidades maranhenses possuem entre $100 \mathrm{a}$ 200 mil habitantes, entre as quais, Timon e Caxias são as mais populosas com 155.460 e 155.129, respectivamente. Com mais de 200 mil; Imperatriz com 247.505 e São Luís com 1.014.837 (IBGE, 2010).

Quadro 1 - Número de habitantes por cidades

\begin{tabular}{|l|l|}
\hline \multicolumn{2}{|c|}{ Número de habitantes por cidades no Maranhão } \\
\hline 5 mil habitantes & 4 cidades \\
\hline 5 a 10 mil habitantes & 33 cidades \\
\hline 11 a 20 mil habitantes & 85 cidades \\
\hline 21 a 50 mil habitantes & 70 cidades \\
\hline 51 a 100 mil habitantes & 16 cidades \\
\hline 101 a 200 mil habitantes & 7 cidades \\
\hline Mais de 200 mil habitantes & 2 cidades \\
\hline
\end{tabular}

Fonte: IBGE (2020), organização dos autores

O estabelecimento das hierarquias e dos vínculos entre as Cidades, bem como a delimitação das áreas de influência, foram divulgadas pelo IBGE, em 2018. Desta maneira, o Maranhão apresenta São Luís (Figura 1), como Capital Regional A²; Imperatriz como Capital Regional $\mathrm{C}^{3}$; as cidades de Santa Inês, Caxias, Bacabal e Pinheiro como Centro Subregional $A^{4}$; e as cidades de Chapadinha, Pedreiras, Presidente Dutra e Balsas como Centro Subregional $B^{5}$.

2 Apresentam contingente populacional próximo entre si, variando de 800 mil a 1,4 milhão de habitantes em 2018. Todas se relacionam diretamente a Metrópoles (IBGE, 2020).

3 A média nacional de população das Cidades dessa categoria é de 300 mil habitantes em 2018, sendo maior na Região Sudeste (360 mil) e menor na Região Sul (200 mil) (IBGE, 2020).

4 Apresenta média populacional de 120 mil habitantes (IBGE, 2020).

5 Apresenta média nacional de 70 mil habitantes (IBGE, 2020).

$\begin{array}{lllllll}\text { Hygeia } & \text { Uberlândia - MG } & \text { v. } 18 & 2022 & \text { p. 14-28 } & \text { Página } 16\end{array}$


Figura 1 - Rede de influência dos centros urbanos e posição hierárquica.

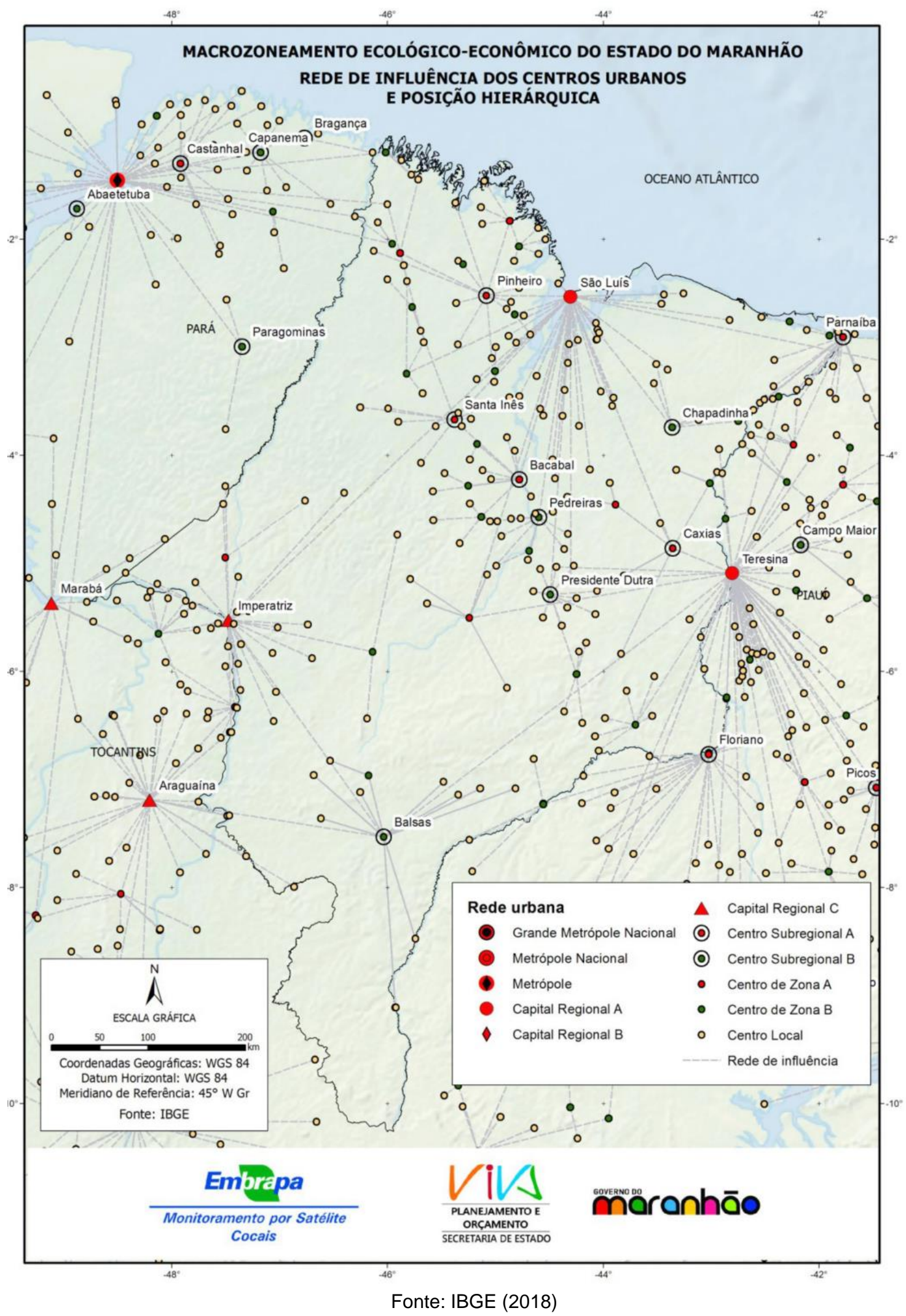


A conexão entre cidades, bem como a influência exercida uma sobre a outra não pode ser analisada de forma isolada territorialmente. De acordo com o IBGE (2018) os centros urbanos possuem alta concentração de atividades de gestão, mas com alcance menor em termos de região de influência em comparação com as Metrópoles, no entanto, todas as cidades existentes no País recebem influência direta, seja de uma ou mais Metrópoles simultaneamente. A região de influência dessas centralidades é ampla e cobre toda a extensão territorial do País, com áreas de sobreposição em determinados contatos, chamada pelo instituto, de conexões externas (Figura 2).

Figura 2 - Conexões externas entre centros urbanos no ano de 2018.

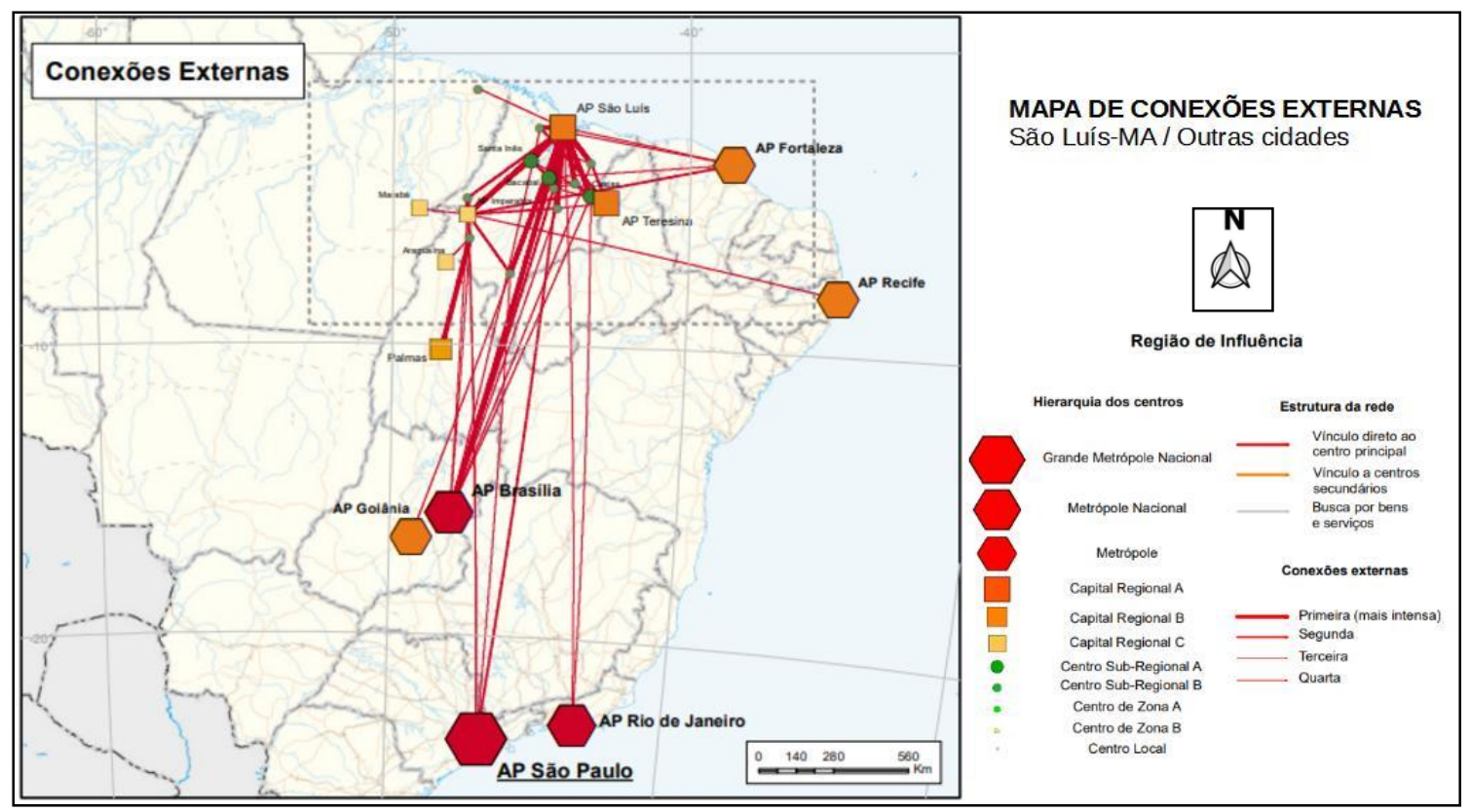

Fonte: IBGE (2018), adaptado pelos autores.

O resultado da pesquisa realizada pelo IBGE (2020) demonstra a força de influência exercida das Grandes Metrópoles Nacionais sobre as Metrópoles Nacionais e as Capitais Regionais. Ainda para o instituto, essas relações de longa distância entre os centros urbanos são geradas por relações de comando e gestão, como as relações entre sedes e filiais de empresas localizadas em Cidades diferentes. A identificação das Cidades que são centros de gestão do território e das ligações entre esses centros é fundamental para estabelecer um nível inicial de referência para hierarquia das Cidades e, ainda, para retratar as ligações entre as Cidades maiores ou dos níveis mais altos da hierarquia urbana; interligadas pelo tráfego aéreo e por rodovias federais, estaduais e vias municipais.

A cidade de São Luís, por ser Capital Regional A, mantém conexão forte com a principal Grande Metrópole Nacional (São Paulo) e outras Metrópoles Nacionais como Rio de janeiro, Fortaleza, Brasília, Goiânia e Belém, através de vias aéreas. Mas, também, mantém forte relação, não só por vias aéreas quanto rodoviária, com outras Capitais Regionais A e C, como é o caso de Teresina-PI e Imperatriz-MA. Se considerarmos a via marítima, a capital maranhense, mantêm conexão internacional, através do complexo portuário. Portanto, as conexões revelam a dinâmica no fluxo de pessoas e mercadorias, com seus aspectos positivos ou negativos.

\section{METODOLOGIA}

Trata-se de uma análise espacial de casos de infecção por Covid-19 notificados pela Secretaria de Saúde do Estado do Maranhão entre os dias 20 de março a 30 de maio de 2020. 


\section{Local de estudo}

O estado do Maranhão possui uma área de $331.983 \mathrm{~km} 2$, oitavo com maior extensão territorial do Brasil e o segundo maior do Nordeste. O Estado possui 217 municípios divididos em cinco mesorregiões: Norte, Oeste, Centro, Leste e Sul do Maranhão e subdividida em 21 microrregiões. De acordo com o IBGE, a população estimada em 2019 era de 7.075.181 habitantes e a densidade populacional era de 19,81 habitantes / $\mathrm{km}^{2}$, destes 4.147 .149 residem na zona urbana.

\section{Levantamento de Dados de Covid-19}

O levantamento de dados sobre a Covid-19 e o número de casos confirmados foi realizado através de dados oficiais da Organização Mundial da Saúde (OMS), Ministério da Saúde, bem como da Secretaria Estadual de Saúde do estado do Maranhão.

Os dados analisados foram dos casos confirmados de Covid-19 pela Secretaria de Saúde do Estado do Maranhão, entre os meses de março a maio de 2020, através dos relatórios diários divulgados no portal da Covid-19 do estado do Maranhão6.

Para compreender a situação sociodemográfica buscaram-se dados no Instituto Brasileiro de Geografia e Estatística (IBGE). A coleta dos dados objetivou compreender a distribuição espacial de casos confirmados por COVID-19.

\section{Confecção de mapas temáticos}

Para a confecção dos mapas coropléticos foram utilizadas a base cartográfica do estado do Maranhão (por municípios) obtida no Instituto Maranhense de Estudos Socioeconômicos e cartográficos do Maranhão (IMESC-MA) e IBGE. É importante salientar que os mapas foram feitos com as bases citadas, por se tratar de um banco público não há a necessidade de direitos autorais. Os dados foram trabalhados utilizando o software QGIS 3.18.2.

\section{DAS PORTAS ÀS ROTAS DA COVID-19: Resultados e discussões}

Durante o período da pesquisa (20 de março a 30 de maio de 2020) foram registrados 35.297 casos de Covid 19 no Estado do Maranhão. Foram 24.101 casos ativos, com 886 internações de enfermaria (189 em hospitais privados e 697 públicos) e 502 internações em UTI (110 em hospitais privados e 392 em hospitais públicos), 976 óbitos e 10.220 recuperados. O percentual de casos confirmados por sexo foi de $53 \%$ (18.650) de mulheres e $47 \%$ (16.647) de homens infectados. O maior percentual entre as faixas etárias foram os de jovens adultos de 30 a 39 anos, com 7.593, o que corresponde a $21,5 \%$ dos casos confirmados, segundo o Boletim Epidemiológico Covid-19 da Secretaria de Estado da Saúde do Maranhão.

Compreendida as conexões existentes entre as cidades maranhenses, além das conexões externas com outros grandes centros urbanos fica mais fácil compreender como o novo coronavírus (SARSCoV-2) chegou ao território maranhense e se estabeleceu através da interiorização que chamamos neste trabalho de rotas da Covid-19. Para chegada do vírus no estado foram identificadas três portas principais: São Luís, através do aeroporto Marechal Cunha Machado; Imperatriz, através do aeroporto Prefeito Renato Moreira e Timon, cidade que compõe região metropolitana de Teresina-PI. Do ponto de vista de expansão do vírus no território maranhense levou-se em consideração o emaranhado de rodovias federais, estaduais e municipais, ferrovias e hidrovias presentes no estado, no entanto, compreendendo que houve diferença no ritmo de transmissão em cada um dos meios técnicos e suas particularidades.

As rodovias federais (Figura 3) que cortam o estado são BR-010; 222; 226; 235; 308; 316; 324; 402; 230; e 135 - um trecho final na ilha do Maranhão. A presença das rodovias federais exerceu significativa importância na transmissão do vírus em todo o estado, tendo em vista a influência das capitais regionais e os centros sub-regionais sobre cidades "menores". A BR 135 liga a cidade de São Luís (epicentro da doença) ao continente, ela provavelmente foi o maior canal de transmissão da

6 https://painel-covid19.saude.ma.gov.br

\begin{tabular}{lllllll}
\hline Hygeia & Uberlândia - MG & v. 18 & 2022 & p. 14-28 & Página & 19
\end{tabular}


COVID-19 no Estado do Maranhão, além disso, faz conexão com a BR 222 que corta a cidade de Chapadinha classificada como Centro Sub-regional B; a BR 316 cruza o estado de leste a oeste e é através dela que se chega a duas grandes cidades, Bacabal e Caxias, classificadas como Centro Sub-regional A; BR 226 dá acesso à cidade de Presidente Dutra, classificada como Centro Subregional $B$, ademais liga o centro ao sul do estado, fazendo conexão com a BR 010 que liga a Imperatriz (classificada como Capital Regional C).

Figura 03 - Rodovias Federais e Estaduais do Maranhão.

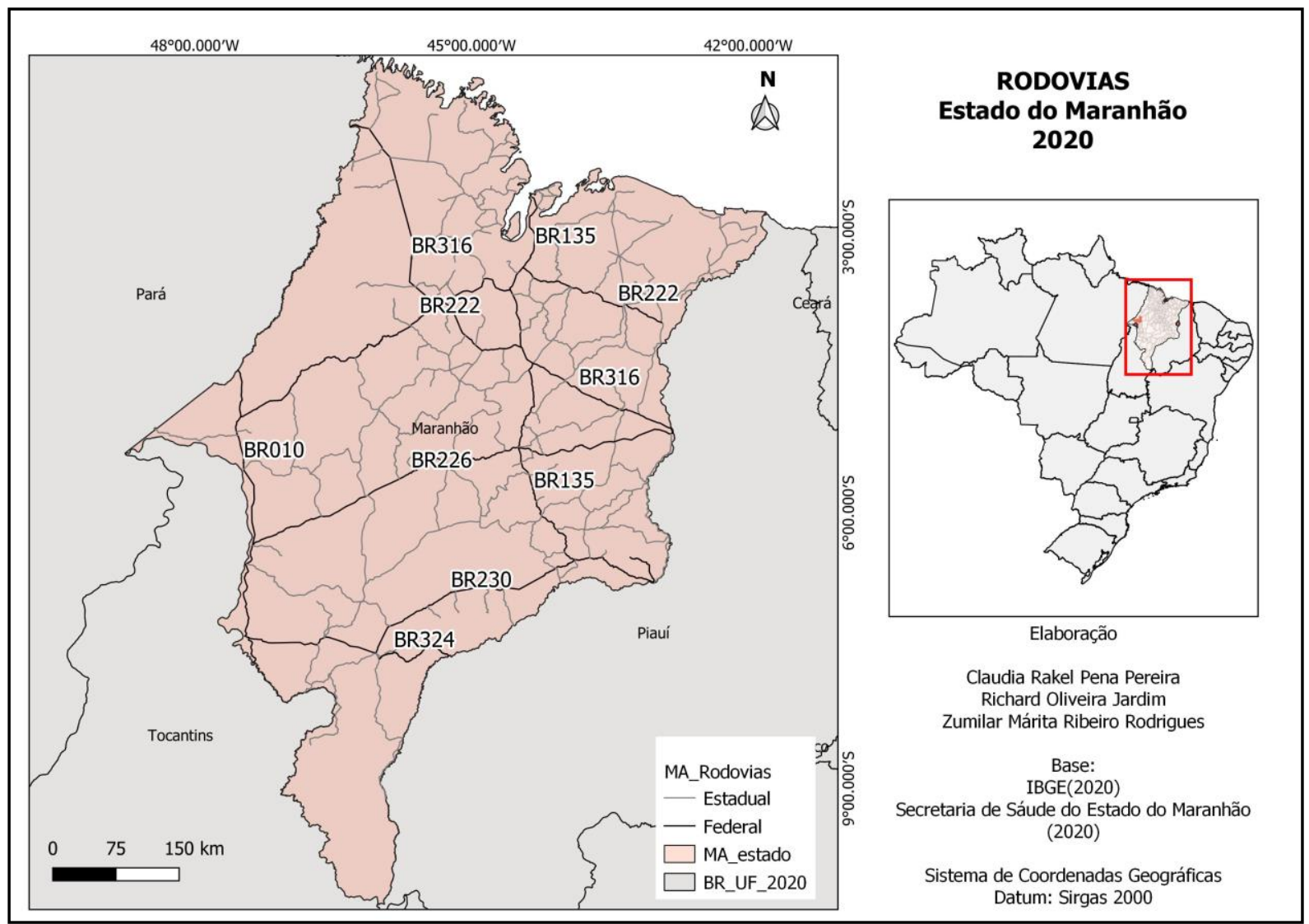

As rodovias estaduais que estão presentes na ilha são: MA201 - Estrada de Ribamar, MA202 Estrada da Maioba, MA203 - Estrada da Raposa, MA204 - Trecho da General Arthur Carvalho, MA207 - Via Expressa, e MA 301-Quebra Pote, zona rural; e as rodovias estaduais no continente, totalizam mais de cinquenta, além das vias municipais que se unem as demais rodovias em algum ponto. A Região Metropolitana da Grande São Luís apresenta um movimento pendular da população principalmente nos quatro municípios que ficam na ilha. Os fluxos presentes na ilha têm como destino, no período diurno, o município polo (São Luís) que centraliza os serviços públicos, as únicas universidades públicas, a maioria das universidades particulares e a zona industrial. O que explica a rápida propagação do vírus na região metropolitana de São Luís.

As ferrovias (Figura 04) influenciaram com menor intensidade a propagação do vírus pelo estado, pois a circulação dos Trens de Passageiros da Estrada de Ferro Carajás (EFC) foi temporariamente suspensa em 24/03/2020 até a última data do recorte temporal para a pesquisa, porém, ainda com circulação de trens de carga durante todo este período. Além da suspensão do transporte de passageiros, o número de ferrovias foi reduzido a duas. A Ferrovia Nova Transnordestina, atualmente, só transporta carga, com $1190 \mathrm{~km}$ em bitola métrica, liga os portos de Itaqui (São Luís/MA), Pecém (São Gonçalo do Amarante/CE) e Mucuripe (Fortaleza/CE), através da Ferrovia São Luís-Teresina e da Ferrovia Teresina-Fortaleza. A ferrovia Norte-sul transporta, principalmente, insumos agrícolas, madeira e minério de maganês. 
Figura 4 - Ferrovias no Maranhão

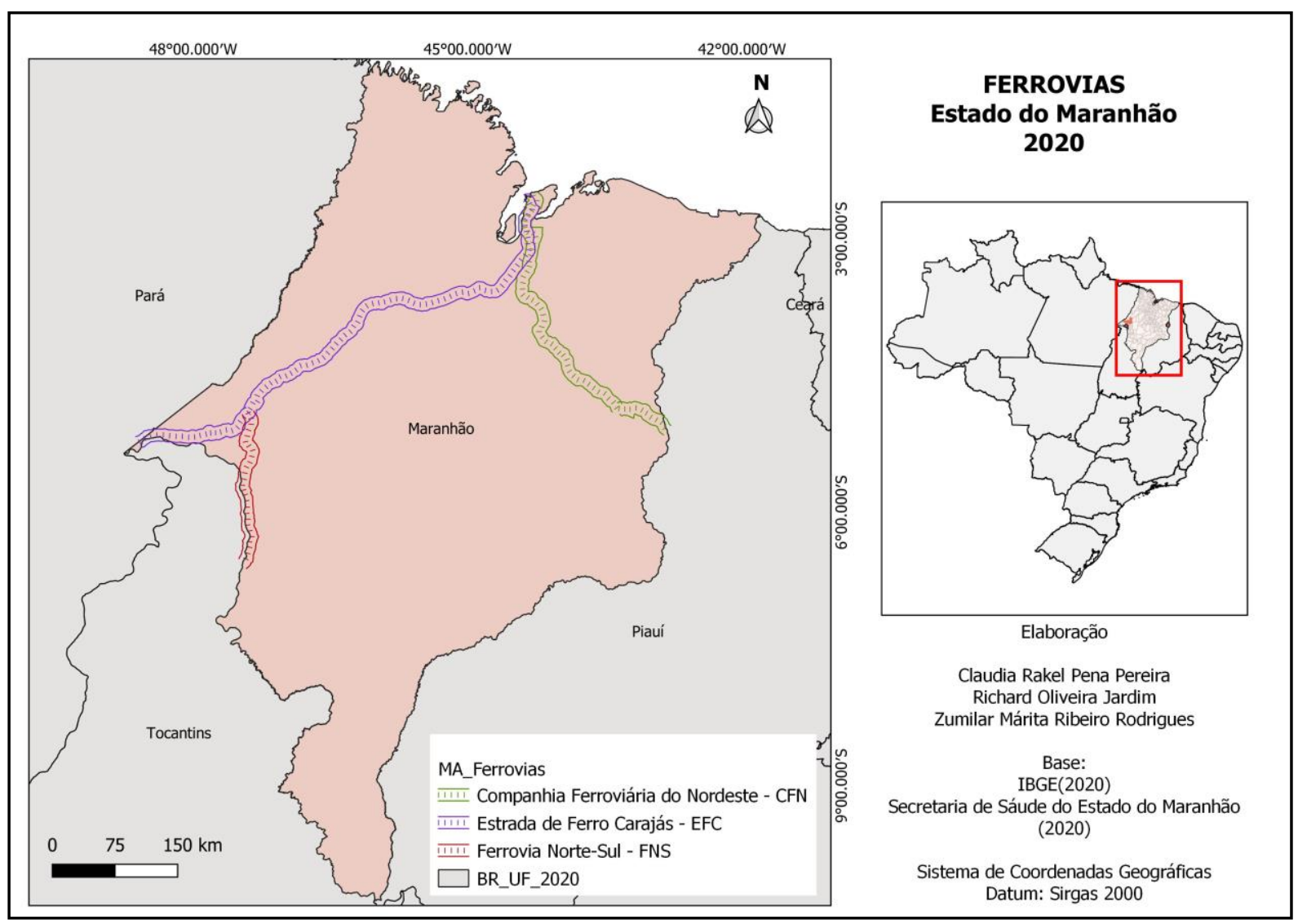

Em relação às Hidrovias, destacamos os três principais rios maranhenses Mearim, Pindaré e Grajaú. Não existem portos organizados ao longo dos rios e o transporte é incipiente, atendendo, principalmente, a população ribeirinha (Figura 5). No entanto, quando observamos a rede urbana do Maranhão, cidades com grande número populacional se encontram as margens dos principais rios. Por exemplo, a cidade de Bacabal com 104.949 habitantes (IBGE, 2019) é banhada pelo rio Mearim. Já Açailândia com 112.445 habitantes (IBGE, 2019) fica a margem do rio Pindaré. Além disso, a travessia São Luís-Alcântara é realizada por embarcações do tipo balsa que faz o transporte de pessoas e veículos no Golfão Maranhense.

O Porto do Itaqui também pode ser considerado como uma porta de entrada e propagação do vírus, o porto movimenta cargas de graneis sólidos e líquidos. As duas cadeias que concentram grande parte do volume são a produção de grãos - exportação de soja e milho e a movimentação de produtos petrolíferos-importação de diesel e gasolina. O porto tem conexão direta com duas ferrovias a Transnordestina e a Estrada Ferro Carajás. O acesso se dá pela rodovia BR 135 e a estadual MA 230.

A densidade demográfica no Estado do Maranhão se concentra basicamente em três eixos: Ilha do Maranhão, Região Tocantina/Balsas e o eixo Santa Inês/Bacabal com Caxias/Timon. Dessa forma, essas regiões ganham notoriedade no estudo da disseminação da COVID-19 por apresentarem grande densidade populacional, importância socioeconômica e prestação de serviços.

A região metropolitana da Grande São Luís (RMGSL) é composta, além de São Luís, por São José de Ribamar, Raposa, Paço do Lumiar, Alcântara, Bacabeira, Rosário, Axixá, Santa Rita, Presidente Juscelino, Cachoeira Grande, Morros e Icatu com área total de 9.304,61 km² e PIB R $\$ 30.771 .746,00$ (IMESC, 2017). É a região com a maior influência socioeconômica do Estado. Caracteriza-se por uma população economicamente ativa, com setor secundário e terciário concentrado em São Luís, onde estão localizadas as principais indústrias de transformação e comércio (IMESC, 2018). 
Figura 5 - Hidrovias no Maranhão

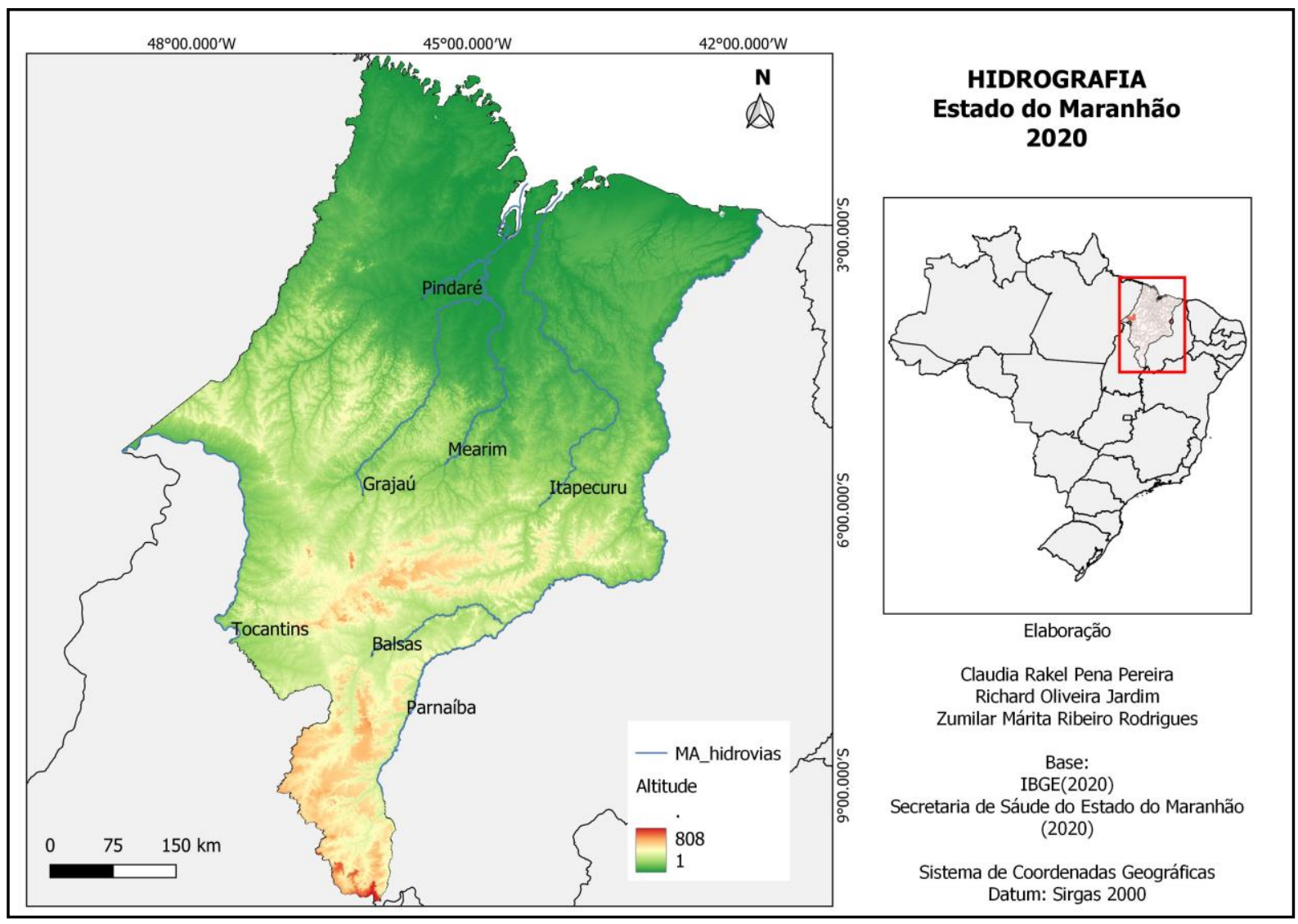

A região Tocantina ocupa uma área de 25.916,60 km², composta por 17 municípios e PIB de $\mathrm{R} \$$ 9.115.956,00 (IMESC, 2017). Imperatriz é a cidade mais desenvolvida da região, destacando-se pela área urbana, população, densidade demográfica e PIB, além de ser centro educacional, comercial e de saúde. A região sul do Maranhão vem passando por um processo de dinamização com a modernização e mecanização das lavouras de arroz, milho, sorgo e principalmente soja. No entanto, Balsas desenvolveu-se através do setor de serviços e recentemente indústrias de beneficiamento de arroz e soja. A pecuária constitui-se como uma atividade complementar praticada em caráter extensivo, com a criação de gado bovino e caprino (IMESC, 2018).

O município de Santa Inês é o mais desenvolvido da região Pindaré, a sua economia gira em torno do comércio, com PIB per capita R $\$ 6.534,75$ (IBGE, 2018). O município de Bacabal concentra a bacia leiteira, parte é consumida e o excedente é enviado para região metropolitana de São Luís, destacase o centro comercial e educacional do município, com PIB per capita R\$30.699,57 (IBGE, 2018). No Oeste do Estado estão localizadas as cidades de Caxias e Timon. Atualmente, as principais atividades econômicas de Caxias são agropecuárias, agroindústria e prestação de serviços, com PIB per capita de $R \$ 11.046,47$ (IBGE, 2018). A cidade de Timon faz parte da Região Integrada de Desenvolvimento-RID de Teresina, sua economia é voltada para o comércio, prestação de serviços e para agricultura de subsistência, com PIB per capita $\mathrm{R} \$ 11.120,68$ (IMESC, 2018).

O primeiro caso de Covid-19 foi identificado na cidade de São Luís em 20 de março de 2020. A dispersão pela região metropolitana de São Luís começa a partir do dia 03 de abril, com 82 casos na capital, 01 em Paço do Lumiar e 02 em São José de Ribamar. No entanto, a segunda cidade a registrar caso foi Imperatriz-MA, em 27 de março de 2020. Nesta última data, São Luís ainda registrava 13 casos. No dia 01 de abril, a primeira infecção foi registrada na cidade de Açailândia, quando São Luís registrava 78 casos e Imperatriz 02 casos. A cidade de Timon registra os 02 primeiros casos no dia 04 de abril. A (Figura 6) representa os três pontos de entrada São Luís (20/03), Imperatriz (27/03) e Timon (04/04). 
Figura 6 - Número de casos de infecção por Covid-19 confirmados no Maranhão (04/04/2020).

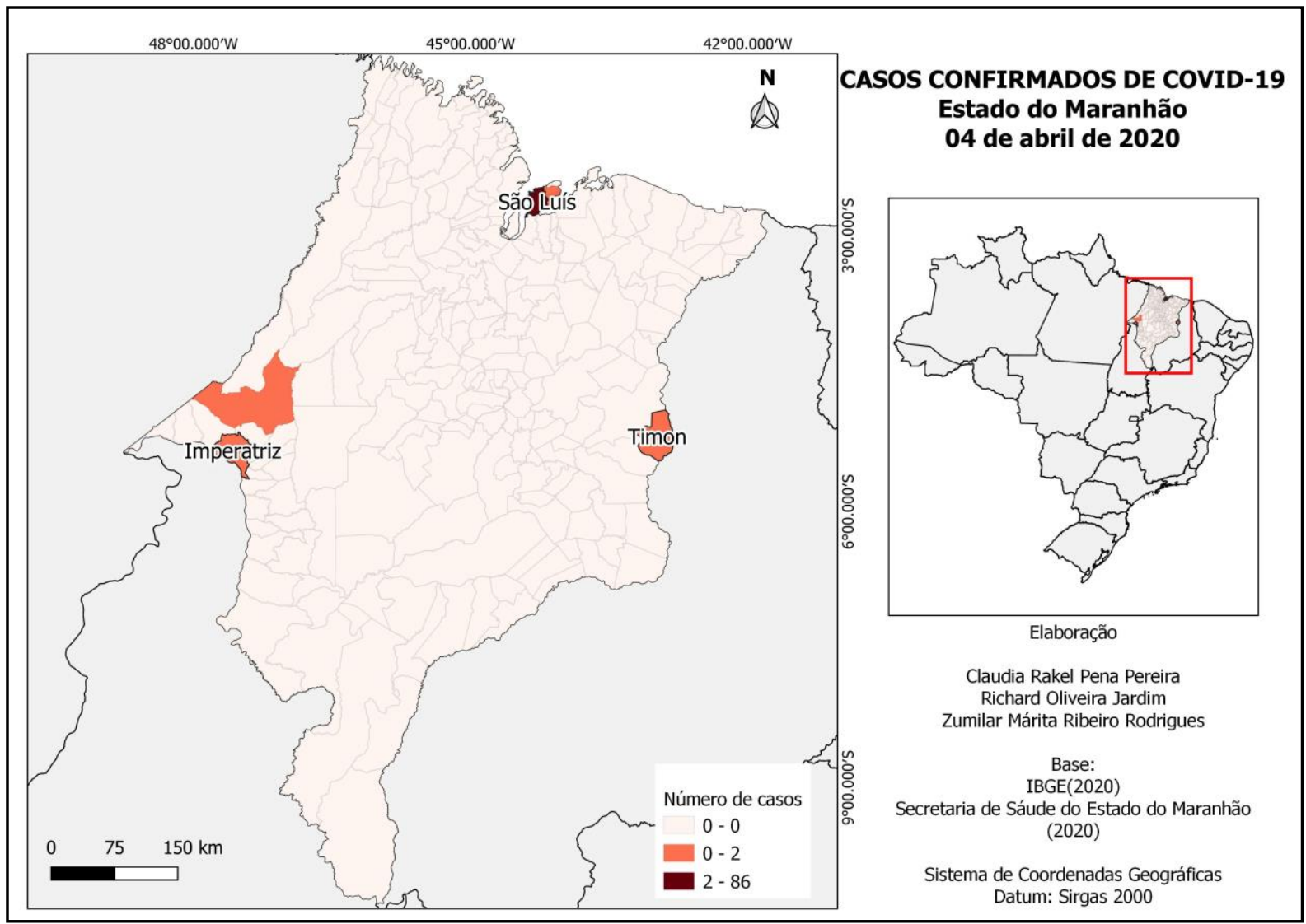

Através dos relatórios diários da Secretaria de Saúde do Estado já era possível monitorar que os casos de COVID-19 estavam se espalhando por todo estado, porém, 98\% dos casos se concentravam na llha do Maranhão, onde estão os municípios de São Luís, São José de Ribamar, Paço do Lumiar e Raposa. Como primeira medida mais restritiva para evitar a disseminação a partir da llha do Maranhão para o continente e vice-versa. No dia 07 de abril o governo do estado, através do Decreto 35722/2020, estabeleceu a suspensão dos serviços de transportes rodoviários e aquaviários intermunicipais de passageiros, restringindo assim os acessos do Estreito dos Mosquitos, único acesso terrestre da ilha com o continente e o serviço de Ferry boat, acesso marítimo. $\mathrm{O}$ art. $3^{\circ}$, deste Decreto, permitia apenas a circulação de ambulâncias, viaturas de polícia e profissionais de saúde em deslocamento, exclusivamente para desempenhar sua atividade, devidamente comprovada. Esse decreto, em grande parte, impediu a grande circulação de pessoas que ocorreria em função do feriado da Semana Santa.

No dia 10 de abril foi possível notar que a dispersão já era bastante significativa. Registravam-se 16 cidades com casos confirmados, sendo eles, com seus respectivos números de casos: Açailândia (01), Cajapió (01), Cantanhede (01), Cachoeira Grande (01), Chapadinha (01), Colinas (01), Santa Inês (01), São Benedito do Rio Preto (01), Viana (01), Urbanos Santos (01), Timon (02) e Imperatriz (05); na grande ilha, Raposa (02), Paço do Lumiar (14), São José de Ribamar (23), São Luís (288).

No dia 20 de abril, um mês depois do primeiro caso confirmado no estado, registrou-se grande expansão entre os municípios (Figura 7) e que esta segue rotas das malhas viárias, principalmente, rodovias federais e interiorização através das rodovias estaduais, obedecendo aos fluxos de conexões entre as cidades, saindo da Capital Regional A, indo em direção aos centros Sub-regionais e posteriormente aos centros locais. Ainda se nota, que os maiores números de casos estavam nos maiores aglomerados urbanos, neste caso, São Luís, Imperatriz, Balsas, Timon e Santa Inês. Nota-se que, neste momento, o maior número de municípios com casos de Covid-19 está na região mais 
próxima da capital São Luís e o sul do estado com menos números tanto de municípios como em casos.

Figura 7 - Infecção por Covid-19 (20/04), rodovias federais e estaduais e ferrovias.

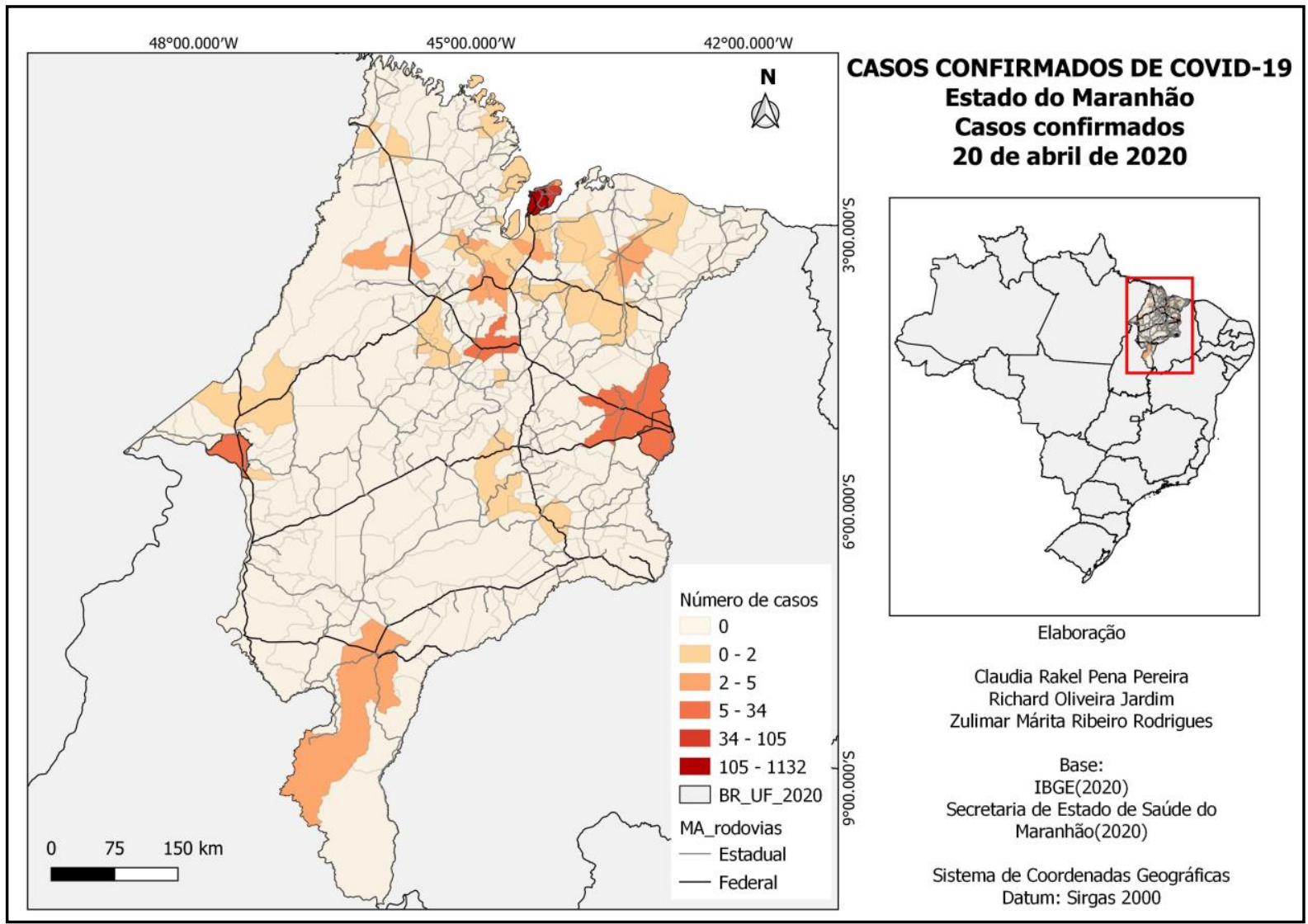

No dia 30 de abril, dezoito dias após as restrições de circulação na Semana Santa, notou-se uma evolução (Figura 8) significativa tanto no número de casos confirmados, quanto na propagação em novos municípios. E de uma forma geral, a propagação pode ser explicada pelas rotas das principais rodovias que cortam o estado. Observa-se que a transmissão do vírus também está relacionada com a rede urbana do Estado, cidades como Cajapió, Cantanhede, Cachoeira Grande, Colinas, sofrem uma grande dependência da capital São Luís.

Embora houvesse restrições na circulação de transporte coletivo, no período da Semana Santa, carros particulares puderam circular para outras cidades fora da llha. Isto provavelmente implicou na disseminação do vírus, contribuindo para o aumento de casos nos municípios que já possuíam casos registrados, como surgimento de casos em municípios antes inexistente. A proximidade com as capitais dos estados do Maranhão e Piauí exerceram maior influência sobre a disseminação do número de casos. Na (Figura 8), nota-se maior concentração de casos de Covid-19 no norte e leste maranhense.

À vista de decisão judicial, proferida pela Vara de Interesses Difusos e Coletivos da Comarca de São Luís, nos autos da Ação Civil Pública no 0813507-41.2020.8.10.0001, o governo do Estado do Maranhão, publicou Decreto no 35.784/2020 estabelecendo medidas preventivas e restritivas que foram aplicadas na llha do Maranhão (São Luís, São José de Ribamar, Paço do Lumiar e Raposa), em virtude da COVID-19. 
Figura 8 - Infecção por Covid-19 (30/04), rodovias federais e estaduais e ferrovias.

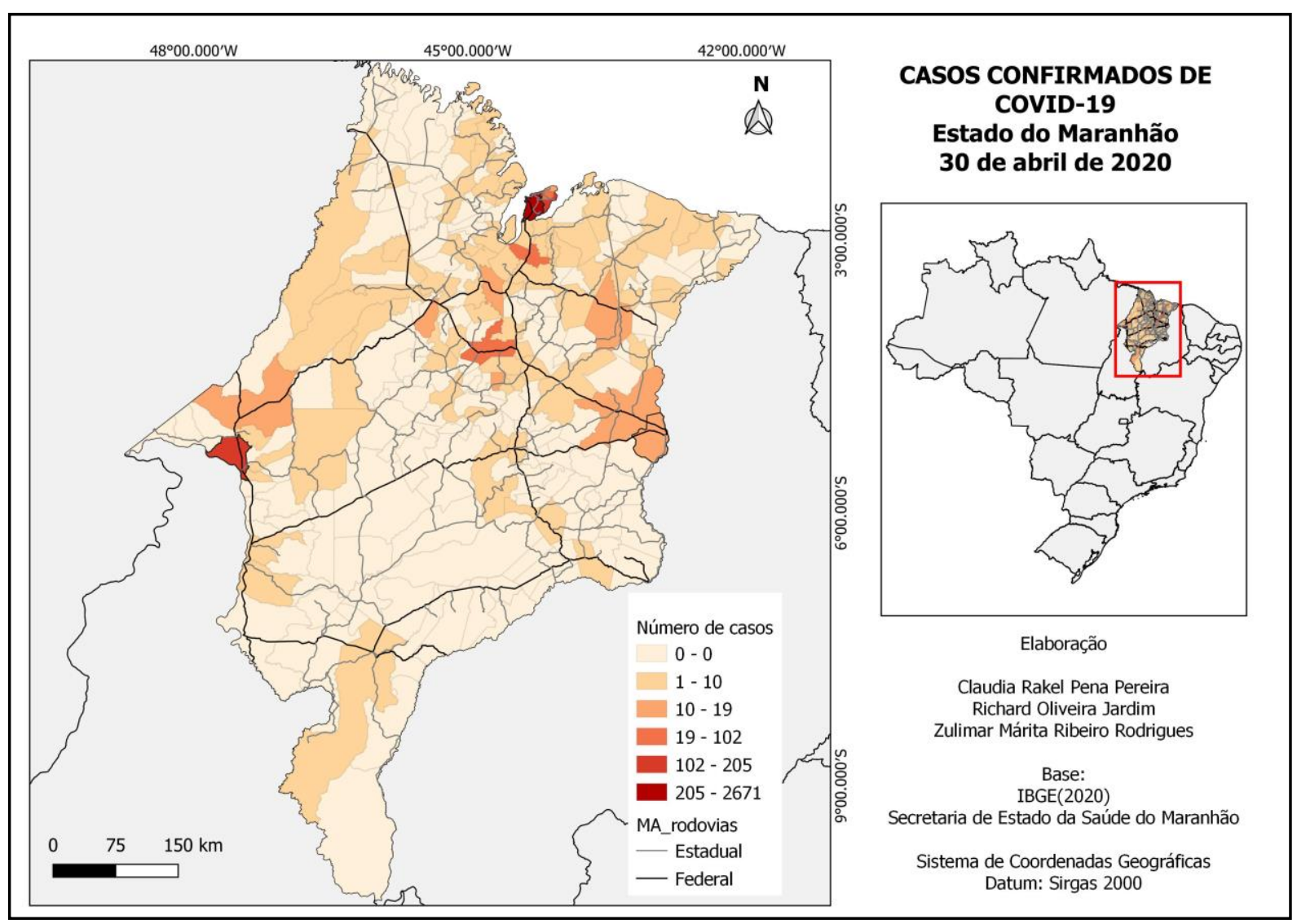

O período do Lockdown ${ }^{7}$ foi inicialmente de 05 a 14 de maio de 2020 e estendido por mais três dias, assim, até o dia 17 do mês corrente. As medidas adotadas pelo governo estadual foram pautadas no Art. 3, incisos I, II e III. Desta forma, foi vedada qualquer aglomeração de pessoas em local público ou privado, em face da realização de eventos como shows, congressos, plenárias, torneios, jogos, apresentações teatrais, sessões de cinema, festas em casas noturnas e similares; em todos os locais públicos e de uso coletivo, ainda que privados, cujo funcionamento seja autorizado na forma deste Decreto, tornou-se obrigatório o uso de máscaras de proteção, descartáveis, caseiras ou reutilizáveis; e, somente foram permitidas atividades consideradas essenciais como alimentação e limpeza, serviços relativos ao tratamento e abastecimento de água, serviços relativos à geração, transmissão, distribuição e comercialização de energia elétrica, gás e combustíveis, médico hospitalar, distribuição e comercialização de medicamentos, serviços funerários, serviços de comunicação, borracharias, clínicas veterinárias, distribuição e comercialização de álcool em gel, locais de apoio a trabalhos de caminhoneiros, fiscalização ambiental e serviços de telecomunicações.

Dois meses após a primeira infecção, no dia 20 de maio, quase todo território maranhense já registrava presença do vírus (Figura 9). Mas, lideravam os casos, São Luís (6.639), Imperatriz (1.102), Santa Inês (293), Chapadinha (443), Pinheiro (229) e Codó (204). Nesta data, apenas 15 dos 217 municípios não registravam casos confirmados.

No dia 30 de maio, apenas cinco municípios não registravam casos confirmados (Figura 10), a saber: Lago do Mato, Loreto, Nova lorque, São Félix de Balsas e São Francisco do Maranhão. Nesta data, São Luís registrou (9.141) casos confirmados, Imperatriz (1.979), Açailândia (795), Zé Doca (945), Codó (800), Chapadinha (846), Santa Inês (1.591) e Timon (364).

7 O lockdown consiste em fechar uma região, interditando vias, proibindo deslocamentos e viagens não essenciais. Cada governante decide de que forma será feito esse fechamento. Além disso, serviços considerados essenciais poderão continuar funcionando.

\begin{tabular}{lllllll}
\hline Hygeia & Uberlândia - MG & v. 18 & 2022 & p. 14-28 & Página & 25
\end{tabular}


Figura 9 - Infecção por Covid-19 (20/05), rodovias federais e estaduais e ferrovias

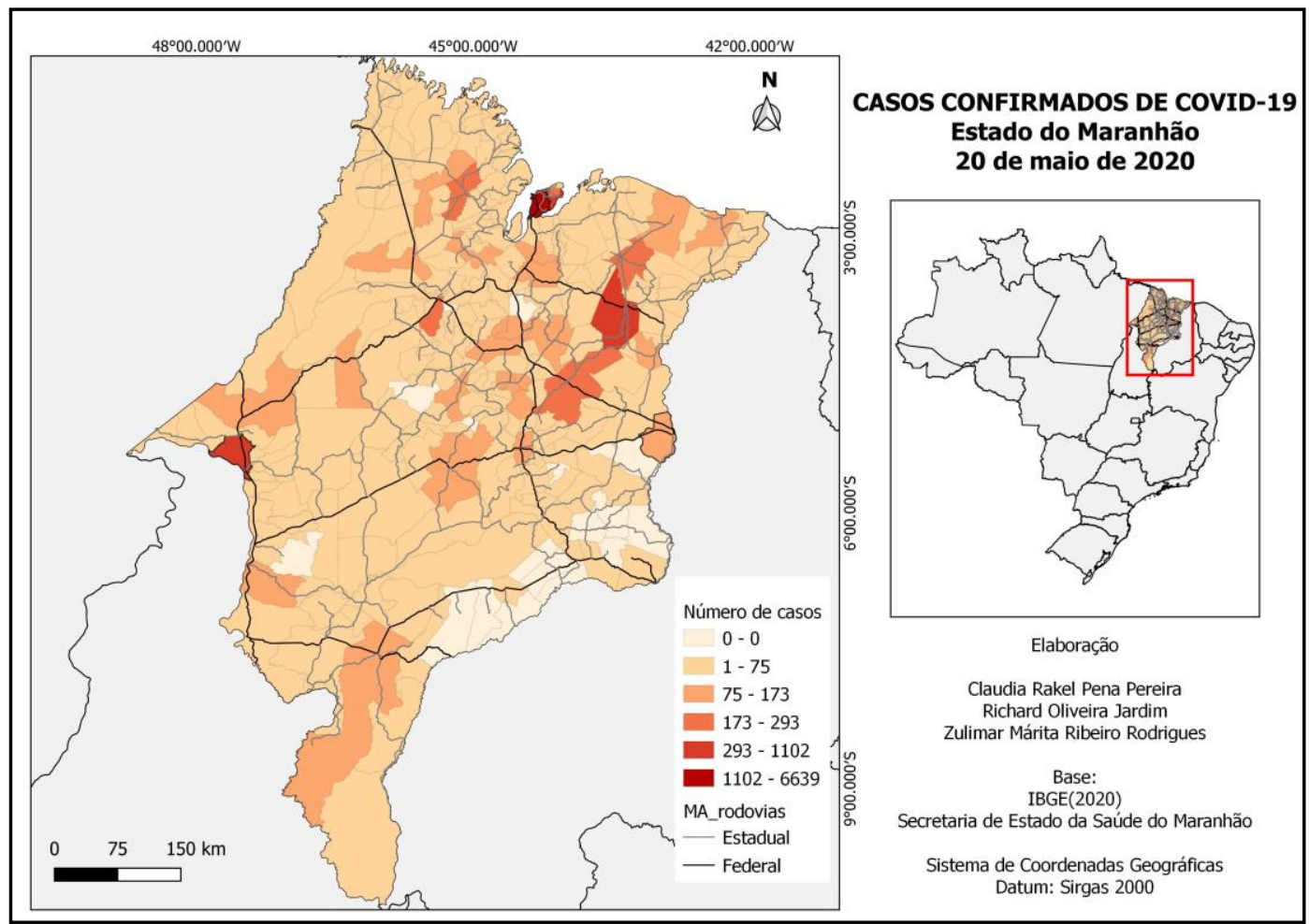

Notou-se, no mapa Infecção por Covid-19 de 30 de maio (Figura 10), que os municípios cortados pelas Rodovias Federais 135 (do norte a sudeste), 222 (leste a sudoeste), 316 (leste a oeste) e 010 (sul a sudoeste) tiveram os maiores números de casos confirmados. A presença destes eixos parece indicar que tiveram muita importância na distribuição espacial do número de notificações no período analisado.

Figura 10 - Infecção por Covid-19 (30/05), rodovias federais, estaduais e ferrovias.

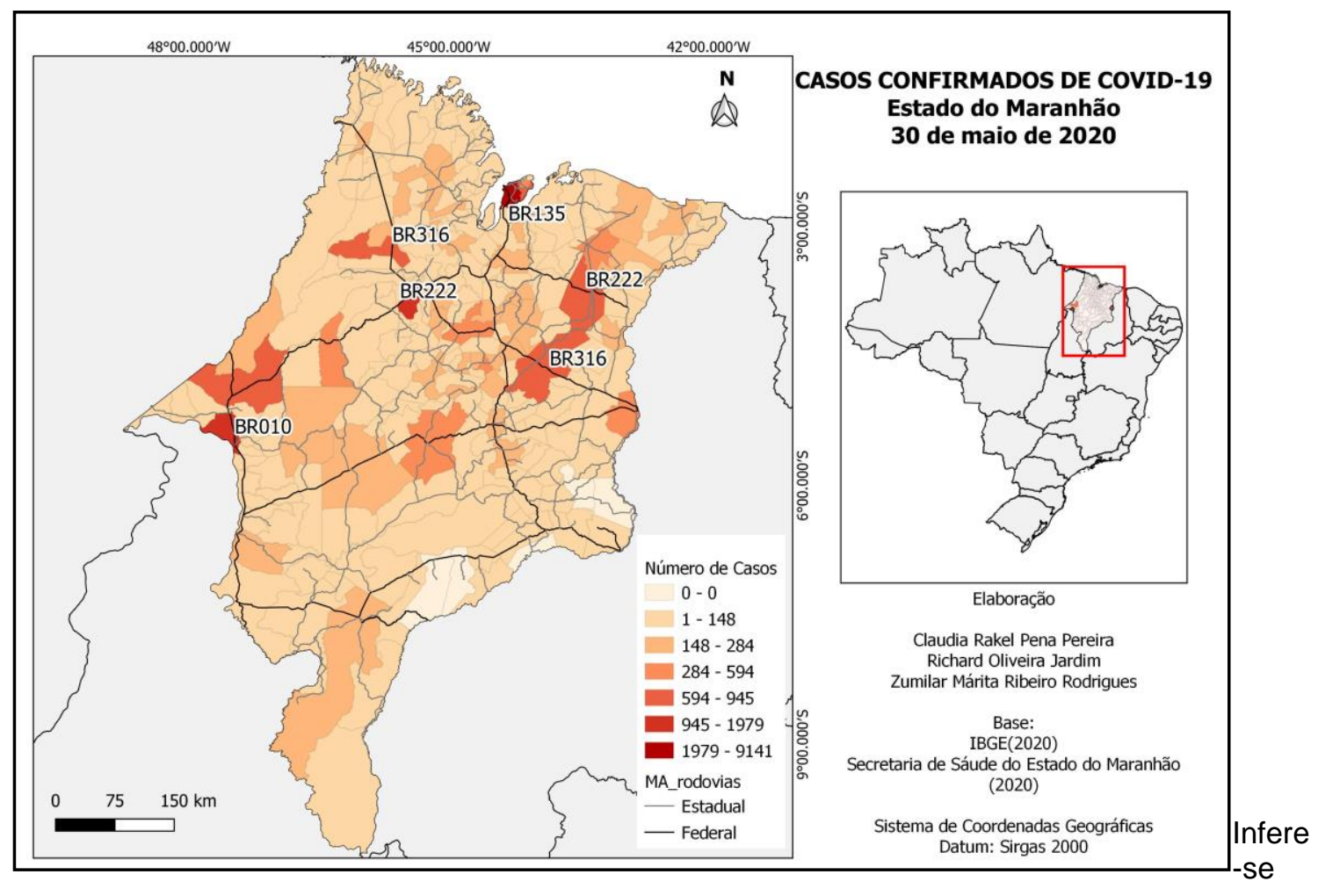


que as rotas de contaminação ocorreram pelos mais variados motivos entre elas por pessoas que se deslocaram de uma cidade a outra para acesso a serviços e equipamentos urbanos como rede bancaria, hospitalar, centros comerciais e trabalhadores de transportes de cargas, entre outras; ratificando a dinâmica da malha viária e da rede urbana no estado.

\section{CONSIDERAÇÕES FINAIS}

No Maranhão, o primeiro caso notificado de Covid-19 foi em 20 de março de 2020, na capital. Um mês depois já havia uma grande expansão entre os demais municípios da Grande Ilha e do continente. Em 20 de maio, apenas 15 municípios dos 217, não tinham registros de casos confirmados. Em 30 de maio, última data analisada, somente cinco municípios ainda não tinham. Portanto, no período estudado, a distribuição espacial foi expressiva e acelerada.

Infere-se que as medidas adotadas pelo governo estadual, como Lockdown retardou a interiorização do vírus no estado, sobretudo, no feriado da semana santa, que tradicionalmente impulsiona o fluxo intermunicipal, principalmente a saída da população da ilha (epicentro da Covid-19) em direção do interior do estado. Portanto, sem essas medidas restritivas, a distribuição espacial seria mais rápida.

Vários fatores contribuíram para as rotas do Covid-19 no estado maranhense. Aspectos mais epidemiológicos da infecção, como o tempo de incubação do vírus, ao início dos sinais e sintomas e quando uma pessoa infectada passou a transmitir o vírus para mais pessoas. Esses períodos foram muito imprecisos ou variáveis para quantificar. O tempo decorrido entre serviços de vigilância e registro das notificações; e a expansão geográfica, de fato, da doença nos municípios. Neste caso, o vírus foi mais rápido.

Ademais os fatores estruturais como a hierarquia urbana e a malhar viária facilitaram a dispersão do vírus e a infecção de mais pessoas; pois, deduz-se que houve um padrão de distribuição semelhante entre ambos. Destarte, pode-se afirmar que o processo de expansão da infecção por COVID-19 pode ser compreendido a partir da dinâmica de pessoas e mercadorias ocorridas no estado do Maranhão, explicitado como um fenômeno geográfico.

\section{REFERÊNCIAS}

BRASIL, 2020. Ministério da Saúde. Coronavírus: o que você precisa saber. Disponível em <www.coronavirus.saude.gov.br> acesso em 09 de novembro de 2020.

BURNETT, Carlos Frederico Lago. [et.al.]. Planejamento e gestão de cidades no Maranhão: o executivo municipal e o controle do solo urbano. São Luís: EDUEMA, 2016.

CORRÊA, R. L. Identificação dos centros de gestão do território no Brasil. Revista Brasileira de Geografia, vol. 57, n. 1, p. 83-102, 1995.

IBGE,2010. Conheça cidades e estados. Disponível em < https://cidades.ibge.gov.br> Acesso em 10 de outubro de 2020.

IBGE, 2018. Conheça cidades e estados. Disponível em < https://cidades.ibge.gov.br > Acesso em 08 de outubro de 2020.

IBGE. Regiões de influência das cidades:2018/IBGE, coordenação de Geografia. Disponível em <http://www.ibge.gov.br/geociencias/cartas-e-mapas/redes-geograficas/15798-regioes-de-influenciadas-cidades.html?=\&t=publicacoes $>$ acesso em 12 de dezembro de 2020.

INSTITUTO MARANHENSE DE ESTUDOS SOCIOECONÔMICOS E CARTOGRÁFICOS. Regiões de desenvolvimento do Estado do Maranhão Proposta Avançada. São Luís: IMESC, 2018.

INSTITUTO MARANHENSE DE ESTUDOS SOCIOECONÔMICOS E CARTOGRÁFICOS. Produto Interno Bruto dos Municípios do Estado do Maranhão: 2015. São Luís: IMESC, 2017.

$\begin{array}{lllllll}\text { Hygeia } & \text { Uberlândia - MG } & \text { v. 18 } & 2022 & \text { p. 14-28 } & \text { Página } & 27\end{array}$


OLIVEIRA, E. X. Regiões de influência das cidades. In: VI Encontro nacional da ANPEGE - Livro de resumos. Fortaleza, Ceará, 2005. CD-ROM.

OMS. OMS afirma que COVID-19 é agora caracterizada como pandemia. Disponível em <https://www.paho.org/bra/index.php?option=com_content\&view=article\&id=6120:oms-afirma-quecovid-19-e-agora-caracterizada-como-pandemia\&Itemid=812> acesso em 10 de dezembro de 2020.

Perspectivas das pesquisas sobre regiões de influência das cidades. In: Anais do X simpósio nacional de geografia urbana. Florianópolis, Santa Catarina, 2007. CD-ROM. PEREIRA, Rafael Henrique Moraes; FURTADO, Bernardo Alves. Dinâmica urbano-regional: rede urbana e suas interfaces. Brasília: IPEA, 2011.

SCHERER, Clauber Eduardo Marchezan; AMARAL, Pedro Vasconcelos Maia de. O espaço e o lugar das cidades médias na rede urbana brasileira. Revista Brasileira de Estudos Urbanos e Regionais, V22, E202001, 2020. https://doi.org/10.22296/2317-1529.RBEUR.202001 